\title{
Complexity Thinking and Methodology: The Potential of 'Complex Case Study' for Educational Research
}

\author{
LINDSAY HETHERINGTON \\ University of Exeter (United Kingdom)
}

\begin{abstract}
Complexity theories have in common perspectives that challenge linear methodologies and views of causality. In educational research, relatively little has been written explicitly exploring their implications for educational research methodology in general and case study in particular. In this paper, I offer a rationale for case study as a research approach that embodies complexity, and I explore the implications of a 'complexity thinking' stance for the conduct of case study research that distinguishes it from other approaches. A complexity theoretical framework rooted in the key concepts of emergence and complexity reduction, blended using a bothland logic, is used to develop the argument that case study enables the researcher to balance the open-ended, non-linear sensitivities of complexity thinking with the reduction in complexity, inherent in making methodological choices. The potential of this approach is illustrated using examples drawn from a complexity theoretical research study into curriculum change.
\end{abstract}

\section{Introduction}

Complexity theories ${ }^{1}$ have been taken up in educational research and more broadly in social science, but relatively little has been written relating ideas from complexity to empirical educational research methodology. This may be, in part, a result of the breadth of thought under the umbrella of complexity theories: complexity scientists working from a perspective of non-linear modeling of complex systems as a productive avenue for research will have a different take on educational research methodology than those viewing complexity from a postmodern or poststructural frame. Different

\footnotetext{
${ }^{1}$ It has been argued that it is misleading to suggest that there is one unified approach called 'complexity theory', as there are multiple theories and epistemological positions that relate to the notion of complexity, suggesting a range of methodological approaches (Alhadeff-Jones, 2008). For this reason, I refer in the text to 'complexity theories' in general, but to the 'complexitytheoretical approach' or 'stance' to denote the theoretical framework used in the work reported in this paper.
} 
epistemological assumptions regarding ways of working with complexity lead to different methodological approaches to exploring complexity. Despite this variability, it has been argued that complexity may offer an "emerging paradigm" in educational research because it "not only provides a powerful challenge to conventional approaches to educational research but also suggests both a substantive agenda and set of methodologies" (Cohen, Manion, \& Morrison, 2007 p. 34). This claim rests on the understanding that complexity theories have in common perspectives that challenge linear methodologies and views of causality, suggest that phenomena need to be viewed holistically and cannot be broken down, require a focus on interactions, and argues for contextual rather than general approaches. Byrne argues that "complexity must become more than a metaphorical apparatus in social science and this can only happen if the complexity frame of reference shapes the actual tools of investigative social science themselves" (Byrne, 2005 p. 96).

In research that takes an explicit 'complexity thinking' approach, it can be argued that complexity theory should inform both the framing of the research problem and the methodological choices in conducting the research. This is not to say that other research approaches are not complex or sensitive to complexity, although they do not necessarily use an explicitly complex theoretical frame. However, as the discussion that follows is based on the premise that for research that is situated within a complexity-theoretical frame, it is important to consider the particular implications of this theoretical perspective on methodology. Methodology is the link between ontology, epistemology and theory informing the research, and the practice of conducting that research. As McCall puts it, "ideally, a methodology is a coherent set of ideas about the philosophy, methods and data that underlie the research process and production of knowledge" (McCall, 2005 p. 1774). Any discussion of a complexity-informed methodology will therefore need to be coherent and theoretically well-grounded, with a clear link between the methods and data, the complexity theoretical perspective informing the work, and the epistemological positioning of the complexity frame. In this paper, I explore the use of a case study approach to research with these considerations in mind. To illustrate the ideas developed, I shall draw on examples from a research study in which I used a complexity theoretical framework to explore the introduction of an 'Opening Minds' curriculum for 11-12 year old students in one UK school. Since complexity is not one unified approach, in order to explain the perspective developed in this paper, I begin by outlining my position in relation to complexity thinking with particular reference to emergence and complexity reduction. My aim with this paper is to show how this complexity lens enabled me to interact with some methodological challenges in educational research in relation to case study approaches, and thus offer a heuristic for other researchers engaging with complexity as a practical research orientation.

Within the complexity literature, different epistemological positions are apparent, which affect the methodological choices researchers make. Richardson and Cilliers offer a helpful discussion of some of these schools of thought around complexity theory in which they focus on 'reductionist complexity science', 'soft complexity', and 'complexity thinking'. This work is from the perspective of the latter, which these authors view as something in between the hard and soft approaches (Richardson \& Cilliers, 2001, p. 5), and which appeals to my sense of the need to maintain both research rigor and a pragmatic epistemological position in which the researcher is situated within and constructs an understanding of the real world of the classroom. Complexity research which focuses more on the reflexive and epistemological dimensions of complexity is exemplified in the work of Morin, who advocates a stance in which: "... complex thought involves the integration of both the complexity of our identity as human beings (Morin, 2001) and the complexity of ethical issues generated by a conception of science understood through its own uncertainty (Morin, 1973, 2004)" (Alhadeff-Jones, 2008, p. 76). From this perspective, the researcher is situated within the classroom and needs to 
engage in a pragmatic sense in researching the 'messiness' of classroom practice. In the example of case study research used in this paper, I chose to adopt a 'complexity thinking' stance to explore an example of curriculum change that was rooted in the epistemology and theoretical work of Osberg, Biesta and Cilliers (Osberg, 2008; Osberg \& Biesta, 2007; Osberg, Biesta, \& Cilliers, 2008), with the intention of taking this work forward in an empirical setting. Focusing on the concept of strong emergence, these authors take seriously the implications of complexity in relation to non-linearity and uncertainty and time-irreversibility, which leads to a form of complexity thinking that is "sensitive to [complexity's] own conclusions...that help us think about the world and knowledge in ways that do not result in, or seek closure" (Osberg, 2005 p. 185). In researching the changing curriculum, I chose to explore case study methods as a way of working with this sensitivity, considering the following questions: (a) what are the resonances and dissonances between 'classic' case study approaches and complexity thinking? (b) what might a 'complexity thinking' approach to case study do differently from others?

\section{Emergence and complexity reduction}

In taking a complexity thinking perspective, it is helpful to keep in mind some key characteristics of complex systems, in which the concept of emergence is crucially important. Assuming that schools can be treated as complex systems ${ }^{2}$, the rich interactions within the system, which have non-linear cause-effect relationships, lead to emergence as a result of self-organization in which different emergent levels all exhibit complex system behavior - in other words, the system does not become less complex if it is analyzed at a smaller scale or 'lower' organizational level (Cilliers, 1998). At the same time, complex systems are open to their environment and respond to environmental or contextual changes, and the response change (emergence over time), though subject to environmental constraints or constraints resulting from the systems' unique history, are also subject to chance and are therefore unpredictable (Cilliers, 1998; Davis \& Sumara, 2006). The concept of strong emergence was particularly important in the theoretical perspective used in this research. The logic associated with this concept argues that emergence in complex systems is not only a result of the impossibility of gathering all the necessary information about the system that would enable us to accurately predict the future, it is a result of the role of chance selection from a range of possibilities, meaning that the future of the system is impossible to determine prior to its emergence (Osberg \& Biesta, 2007). Conducting case study research from a complexivist perspective means considering the implications of the concept of emergence as a crucial element in complexity thinking ${ }^{3}$, and this entails consideration of emergence in relation to system organization and change in the system over time. In the discussion developed in this paper, I therefore explore the importance of this concept for paying particular attention to interactions and relationships within the different formal and informal organizational layers within the school system on the one hand, and the necessity for a temporal element to the case study on the other.

\footnotetext{
${ }^{2}$ There is insufficient space to argue this point in this paper, but refer to Davis and Sumara (2006) for further reading on the subject.

${ }^{3}$ Indeed, I would argue that even where research is not explicitly using the language of complexity, where there is sensibility towards exploring uncertainty within social systems that have the capacity to self-organize, and where the interactions and relationships between different aspects of the system are considered, then the research could be considered complexivist in some way. I would also argue that for such research, the language of complexity can offer useful insight, as different use of language aids shifts in thinking, for example in engaging with thinking differently as a result of engagement with non-linear perspectives on causality (Kuhn, 2008).
} 
Alongside emergence, complexity reduction is an important key concept, which refers to ways in which the complexity of social systems may be reduced, for example by reducing opportunities for dialogue. The notion of complexity reduction is important in education and schooling as a number of authors have noted that aspects of the school system, including timetables, curricula, classroom organization and layout, and school hierarchies may all contribute to the reduction of the potential complexity of schooling, or mitigate against the conditions for emergence in various ways (e.g., Biesta, 2010; Frelin \& Grannas, 2010; Simons \& Olssen, 2010). Complexity reduction is also important in the context of research as well as education, because the act of conducting research also acts to reduce the complexity of the system.

If complexity is characterized by rich interactions between large numbers of diverse elements within open systems, with the operation of positive and negative recursive feedback loops influencing these interactions, then complexity reduction can be viewed as acting against these features of complexity appearing or continuing. Biesta (2010, p. 7) takes this line in defining complexity reduction as having to do with: (a) reducing the number of options for action for elements within a system; and (b) impacting on the recursivity of the system by constraining the language used in the system. Complexity may be reduced or constrained through, for example, minimizing the interaction of a system with its environment, minimizing the opportunity for interaction within the system, or through decreasing the number of elements within the system. It appears, therefore, that complexity can be reduced in various ways in the process of educational research: the researcher's understanding of complexity, choice of theoretical approach, choice of methods and the artificial boundaries set around the system being researched can all be seen as forms of complexity reduction. Consideration of the implications of such reduction on emergence raises questions over whether complexity reduction can be theorized within a complex epistemological, ontological or methodological frame. Fenwick (2010) characterizes this problem clearly:

The premise is that complexity is the primary condition of life. Interactions among all living elements are dynamic, non-linear and emergent. Therefore ... predictability and consistency ... may only be accomplished through reducing the complexity of the system, i.e. through limiting the number of possible variables and reducing the 'recursivity' of the system and its potential for emergence. But while it may seem natural to take this analytical step, how in fact do we analyse the concept of complexity reduction? Complexity theory itself may not be helpful ... for it does not theorise its own absence. (Fenwick, 2010 p. 58)

Fenwick goes on to discuss the problem of theorizing complexity reduction using complexity thinking, which relates to the anti-reductionist line in complexivist thought. We can suggest that complexity reduction occurs through mechanisms, which remove or inhibit elements needed to produce complexity and emergence. But if we accept that the whole is more than the sum of its parts, then, as Fenwick suggests, "the less-than-whole cannot simply be assumed to be the reduction or suppression of these parts" (Fenwick, 2010, p. 58). Therefore, a simple assumption that complexity reduction entails the removal of some parts of the system, which then prevents emergence, cannot be reconciled with the concept of strong emergence in complexity theory. Instead, the complexity thinking perspective suggests that in any act of complexity reduction (for example through choosing a particular theoretical framework for research), the complexity of the system in which the researcher is embedded may also emerge in unpredictable ways as a result of the researcher's interaction with the system (Fenwick, 2010; Rasmussen, 2010). Rather than complexity reduction existing in opposition to emergence, the two concepts can be seen as working at the same time, using the 'both/and' logic common in poststructural thinking and in some perspectives on complexity theory (Pinar \& Irwin, 2005; Smitherman Pratt, 2008). Thus, complexity reduction and emergence are simultaneously part of the complex way of thinking in this 
research stance. In the following discussion, I use the concepts of emergence and complexity reduction to explore an approach to case study that is rooted in complexity thinking.

\section{Case study approaches}

A case study is expected to catch the complexity of a single case ... We study a case when it itself is of very special interest. We look for the detail of interaction with its contexts. Case study is the study of the particularity and complexity of a single case, coming to understand its activity within important circumstances. (Stake, 1995 p. xi)

As Stake suggests, case study is an approach to social science research that focuses on particular cases that are of relevance to the focus of research interest. Distinguished from experimental research which may be conducted on small numbers of cases by a naturalistic approach rather than direct control of variables (Hammersley, 2004), case study is often considered an approach to research rather than a methodology that can be "easily summarized as a single, coherent form of educational research" (Chadderton \& Torrance, 2011, p. p. 53). Case study has developed from a wide range of influences that affect the different purposes of and methods for studying cases in the social sciences, and as a result, there is no one 'case study methodology' but rather a general consensus that case study emphasizes 'study-in-depth'.

The unique and particular nature of case study is seen as both a strength and a limitation. On one hand, it can take an example of an activity and explore it in depth, using multiple methods to achieve a thick description. On the other hand, the unique nature of the case mitigates against generalizability, in spite of the argument that case studies support readers in naturalistic generalization (Stake, 2005). There is also a question over the role of the researcher in researching and interpreting the case. Should the description of the case aim to produce an account of the case from its own perspective, giving voice to the participants, or should the case study be presented from an external, more objective perspective focused around the particular theoretical or evaluative special interest around which the case study is developed? Judgments made about the quality of case study research depend to some extent on the particular case study approach within which they are located. In this sense, the theoretical/epistemological positioning of the research is crucial in understanding the methodological choices made in conducting a case study and their rationale, as this impacts on the balance between the strengths and limitations of the choices made. The advantages and limitations of case study research are therefore multiple and contrasting depending on the particular case study approach taken in any given research, which is influenced by the epistemological and methodological perspectives of the researcher. A complexity thinking approach to case study will therefore be distinct from, for example, an ethnographic approach, despite some similarities in methodology.

It has been argued that because of the unique nature of any complex system (in terms of its embodied history and relationship with other systems), any knowledge about that system must be contextual (Byrne, 2005). From this, it has been suggested, particularly in the work of Byrne $(1998,2005)$, and Haggis $(2007,2008,2009)$ that a form of case study methodology is an appropriate choice for complexity-based educational research, emphasizing as it does the local and contextual nature of complexity knowledge (Cilliers, 1998). However, many of the examples of empirical research in the complexity and education literature draw on case studies, with it being implicitly understood that this approach is reasonable. These case studies have often been conducted using interpretive or mixed methods, which might include quantitative elements such as interaction mapping but again, the rationale for these choices is not always explored. 
Texts advising on case study as a research approach suggest that a range of methods can be used to collect information about the case. Sources of data might include interviews, documents, observations and questionnaires conducted both within and beyond the physical location of the case (Stake, 1995). In educational research, case study tends to focus on a "disciplined, qualitative mode of inquiry", making use of "naturalistic, holistic, ethnographic, phenomenological and biographic research methods" (Stake, 1995, p. xi). Such a use of a range of interpretive methods is a logical one, but acknowledging complexity suggests one to pay attention to the ways in which these methods afford insight into the relations and interactions within the case, and also to the temporal influences within the case. However, Hitchcock and Hughes (1995) suggest that case studies are distinguished less by their methodologies than by the subjects of their inquiry and that they are particularly valuable when the researcher has little control over events. Authors have categorized case studies in various ways, often based on the reason for undertaking the study as much as any difference in method ${ }^{4}$. For example, case study might be used to describe and understand a particular case, or to develop conceptual categories and link to theory, or to illustrate in depth some issues derived from larger-scale analysis. In the context of complexity theory, the approach to case study might be defined as descriptive and exploratory, since the effort is oriented towards exploration of the 'present' in order to enable the creation of something new.

In the following, I discuss the potential of an approach to case study based on a complexivist epistemology, exploring how complexity thinking might influence the methodological choices made in taking such an approach that are both similar to and distinct from other case study approaches. The discussion is illustrated using an example of a case study conducted from this perspective, into curriculum change in one school, and makes use of the key concepts of emergence and complexity reduction introduced earlier.

\section{Complexity thinking and case study}

The way in which case study can be taken up as a methodological approach related to complexity requires careful thought, as complexity offers the potential to re-think common research methods and strategies as a result of its particular ontological and epistemological base, thus influencing the research design, methods, and analytical or interpretive techniques that might be considered. The discussion of complexity thinking and case study in this paper focuses on a number of key areas that highlight aspects where complexity thinking entails particular research decision-making in the pursuit of case study. These are causality, boundary-setting, and researcher location, based on key areas of discussion within case study research considered by Gomm, Hammersley and Foster (2000, chapter 12). For each element of discussion, I illustrate the principles considered with reference to a piece of case study research conducted using the complexity thinking perspective outlined earlier in this paper. The data collection for this case study took place over three years and was undertaken for a research project which aimed to explore the introduction of a new, flexible learning to learn based curriculum for 11-12 year olds in one school. The curriculum, called "Opening Minds", was introduced in response to the teachers' perceived need for students to develop their skills as learners and I was interested in particular in how both Opening Minds and science teachers responded to the apparent flexibility experienced as a result of changes to national policy. I was also interested in exploring how the complexity theoretical

\footnotetext{
${ }^{4}$ For example, Yin (1984) identifies exploratory, descriptive and explanatory case studies; Merriam (1988) categorizes descriptive, interpretive and evaluative case study; Stenhouse (1985) identifies case studies that are ethnographic, action-research, evaluative or educational; and Stake (1994) separates case study into three types, intrinsic, instrumental and collective.
} 
perspective of Osberg and Biesta (Biesta \& Osberg, 2007; Osberg \& Biesta, 2007) could be used as a lens to explore these issues given that the flexibility of the new curriculum appeared to have the potential to respond to complexity's challenge to the traditional epistemology of schooling ${ }^{5}$. In this paper, theoretical considerations are shown in standard font, with discursive illustration shown in italics, for clarity.

\section{Causality}

In case study research, it has been suggested that one advantage of case study is that they allow the exploration of causal processes as a result of study in depth over a period of time, though approaches to such exploration of causality can differ. For example, some argue that causal chains within case study could potentially be identified through comparative analysis, whereas others argue that a narrative approach which recognizes the multiple pathways by which an outcome could be reached is a crucial element of case study (Gomm et al., 2000). In complexity thinking, the dynamic nature of complex systems and the concept of emergence mean that it is impossible within this framework to ignore the importance of change and time, which ties closely to this debate in case study research. Paying attention to the dynamic nature of a complex case study does not mean that it is possible to easily discern cause and effect or be able to use descriptions of system trajectories to be able to predict future behavior (Haggis, 2008). As a result of the multiplicity of interactions and feedback within a case, and the non-linear causality within complex systems, one could argue that in a complex case study, the narrative rather than comparative approach to case study is likely to be more appropriate. However, in addition to this, the concept of strong emergence (which argues that prediction is not only difficult but inherently impossible in a complex system) means that case studies of such complex systems cannot enable prediction of future behavior. This does not mean that such descriptive and exploratory case studies of complex systems have no research value, however, since the exploration of the emerging present of a system through time can help us think about the processes within the case, with a view not to gaining answers about how this case will proceed, or indeed about how all such similar cases may proceed, but instead with a perspective of openness to possibility for the creation of new knowledge, rethinking cases, and taking ideas in new directions. This is linked to the notion of the location and role of the researcher in the exploration of complex cases, which I consider later in this paper.

The importance of change over time in exploration of a complex case study entails a longitudinal research design. However, further questions about the methods used to explore the case remain. One possible approach to managing both the need to explore a case in depth, over time, that is responsive to emergence within the case is through the use of responsive multiple methods, such as advocated by Kincheloe and Berry (2004) in their interpretation of bricolage, or by Law (2004) in his "method assemblage". Both of these approaches argue for an inclusive and responsive approach to method that is better able to deal with the uncertainty and complexity of real-world systems in a way maintains research rigor. Kincheloe's approach is characterized by an openness to possibilities, the need to re-read and reflect on data from a range of viewpoints, and the introduction of different methods or tools as one moves deeper into the complex web of study (Kincheloe, 2001, 2005). The bricolage approach has been subject to critique by those who feel it lacks theoretical clarity and in-depth skill in a given discipline, but Kincheloe and Berry (2004) argue that it is in fact not an avoidance of the question of rigor and quality. Instead, they suggest that the ability to respond to the emergent data and to open spaces for thought is exactly what would be required for rigor and quality in

\footnotetext{
${ }^{5}$ Of necessity, only excerpts and illustrations from the research can be used in this paper. For more detailed consideration of the substantive and methodological issues encountered, please see Hetherington (2012).
} 
researching the complex social world. From a complexity perspective, one could argue that bricolage embraces both order and disorder in a way that ties closely to a complexivist interpretation of education (Alhadeff-Jones, 2012). Despite not being explicitly framed from a complexity theoretical position, Kincheloe and Berry's argument clearly demonstrates complexivist sensibilities and I believe that such an approach enables the researcher to explore issues related to causality and emergence in a complex case study from clear methodological ground.

In my Curriculum Change case study, I chose to adopt a bricolage approach to enable me to respond to emergent developments within the case as I worked within it. The research was conducted over three years, and although I was limited in the time I was able to spend there (this was not an ethnographic study), I returned to the school several times per term over the course of each school year. In order to enable me to adapt my methods to the emerging case study, I began with three principle methods, which I felt would allow me to gain a broad picture of the case interviews, observations and questionnaires. I interviewed teachers and students individually, observed Opening Minds lessons, and used a broad questionnaire with attitude scales and openended questions for both staff and students. These strategies are not unusual in case study research, and nor is the ongoing reflection on the data collected as a result and the use I made of a research journal. One issue was that these methods could only provide a snapshot of the case at a particular time, so it was necessary to include questions that would elicit participants' perspectives of the past, present and future of the case. Also, given the focus on complexity thinking, I needed to ensure that I could respond to the changing case. This meant that I began to adopt alternative methods when it appeared that I needed more information about an emerging aspect of the case. For example, in my initial data it appeared that creativity and reflection were key foci of the new curriculum from the teachers' perspective, but how this was enacted in practice was unclear within my observations. I therefore adopted two further approaches to explore this issue: exploration of the students' work in lessons, and interviews with focus groups of students. A second example involved a move to observation of teacher professional development in relation to the Opening Minds curriculum, as the sense of what the Opening Minds curriculum entailed and the pedagogy associated with it appeared to be increasingly constrained over time. I therefore gained access to observation of teacher in service training over two years as a way of accessing a different perspective on this question.

As highlighted by Haggis (2008) and in the above discussion, the interactions and feedback loops within complex systems suggest that exploration of a case in order to construct a narrative involves attempting to map interactions and relationships within the case, not with the aim of identifying cause and effect in order to be able to predict, but in order to achieve the richest possible picture of the ongoing processes. In a school setting, there are imposed structures which constrain the interactions (see later discussion of complexity reduction), but there are also emerging groups and relationships. This relates not only to the question of causality in case study research, but also to what is considered to be the case, the question of multiple cases, and the issue of how to draw the boundaries around the case. I now turn to explore this element in more depth.

\section{Case boundaries}

Chadderton and Torrance (2011) highlight a number of varying ways in which case study has been used in social science, stating that:

What is common to all approaches is the emphasis on study-in-depth; but what is not agreed is where to draw the boundaries of the case, and the extent to which the researcher can produce a definitive account of 'the case', from the outside, so to speak, rather than a series of possible readings of 'the case' from the inside. (Chadderton \& Torrance, 2011, p. 53) 
This suggests that within a case study approach, particular ways of identifying boundaries and locating the researcher in the case, and therefore the particular type of case study conducted, is flexible and dependent on the theoretical basis of the research. Part of the problem in defining the case in complexity-theoretical research stems from the open, unbounded nature of a complex systems perspective, and relates to the problem of complexity reduction. Choosing boundaries to set around a case entails focusing in on particular aspects and thus excluding other aspects and therefore reducing the complexity of the case. Seeing the world from a complexity perspective involves viewing it as a network of multiple, connected, open systems which can vary dramatically due to their unique trajectories of emergent development and unique interactions with other, larger systems. It also means that however the case is bounded, the multiple interactions and connections with systems beyond that defined as the case make it impossible to set limits on the research due to the infinite range of interactions that impinge on the case itself. Equating a particular complex system with a particular case appears to be a reasonable strategy (so long as one is confident that the case can reasonably be seen as a complex system), bearing in mind that a complex system has a "dynamic coherence" (Davis \& Sumara, 2006, p. 100) even if it doesn't have clearly defined boundaries. Defining any complex system as the case, which is the focus of research implicates the researcher in setting boundaries on the research because of the interwoven and complex nature of multiple connections and interactions between complex systems. As Byrne puts it: "What is a system of interest at any point in time is defined by observation and action. Boundaries depend on what we are looking for and at. This is not to say that boundaries are arbitrary, relative or unreal" (Byrne, 2005, p. 105). Whether the boundaries placed follow patterns that exist in the complex systems in the real world or not, the necessity of locating a focus of interest and setting boundaries on what will be included in the research is an act of complexity reduction that locates the research within the research field and in the system that is researched which, along with the developing research, may emerge differently as a result of engaging with that research.

Chadderton and Torrance's approach to case study is to consider a definition of case study that combines a focus on policy with a specific location. This creates a focus on the social construction of the case rather than on individuals as cases, where the study of individuals is then carried out from the position of asking what 'the case' looks like from that individual's point of view. Using the complexity thinking approach considered in this paper, we can extend this argument to collectives as well as individuals. This is an interesting approach to case study in relation to complexity theory for two reasons. Firstly, it is compatible with a notion of nested levels in the complex system that is the location of the case, and is also compatible with the notion of multiple, interacting perspectives. Secondly, the idea of coherence around a policy focus is a useful way of creating boundaries around the research to enable the case study to proceed, as it allows the case to incorporate multiple interacting complex systems and avoids the problem that "too often in the past the boundaries of the case have been assumed to be coterminous with the physical location of the school" (Chadderton \& Torrance, 2011 p. 54). From a complexity perspective, the school might constitute a complex system at a given moment in time, but the assumption is that each complex system is embedded in and interacting with others, in a dynamic trajectory in time. Whilst one could construct the boundaries of the complex system and the case as the same, such that a complex system could be taken as a case, it does not necessarily have to be so. Morrison's discussion of the implications of complexity for educational research takes a similar direction, though he is not explicitly discussing a case study methodology. For Morrison, complexity theory:

... suggests that the conventional units of analysis in educational research (e.g., individuals, institutions, communities and systems) should merge, so that the unit of analysis becomes a web 
or ecosystem (Capra, 1996, p. 301), focused on, and arising from, a specific topic or centre of interest (a 'strange attractor') (Morrison, 2008, p. 28).

Cohering the notion of the 'case' around a concept of a developing curriculum, for example, facilitates the sketching of boundaries around the 'case study', albeit temporary and shifting ones, that is linked to the area of exploration that is the focus of the research.

Following this suggestion, I chose to focus my case study on one school's particular response to changes to the national curriculum which enabled them to adopt and design a new 'Opening Minds' curriculum, based on the Royal Society of Arts' Opening Minds principles (RSA, 20082012), thus focusing the case study on a key policy perspective within one specific location. However, although this was my 'case', I also adopted an approach in which I needed to consider not just the perspectives of individual teachers and students in relation to the Opening Minds curriculum, but also how common school groupings such as classes, year groups, the Opening Minds teaching team, the science teaching team, and the staff body interacted with each other and the changing curriculum. I chose to adopt and approach that used a 'multiple case' perspective within this larger case study, where I chose to view individuals and groups as interacting 'cases' in order to help me organize my thinking. Seeing groups as 'complex cases' that learn, adapt and change alongside individual perspectives formed part of my exploration of the complexity of my case study, specifically informed by a complexity thinking framework. Figure 1 shows one of the hyperlinked 'case maps' I used to think about group and individual interactions within the case study as a whole. These maps were used during my ongoing collection and exploration of the data to highlight relationships and interactions as I coded qualitative data, to group and regroup data and emerging perspectives over time, and to consider the influence of pre-existing school structures alongside more self-organizing individual and group relationships in relation to the developing curriculum and pedagogy.

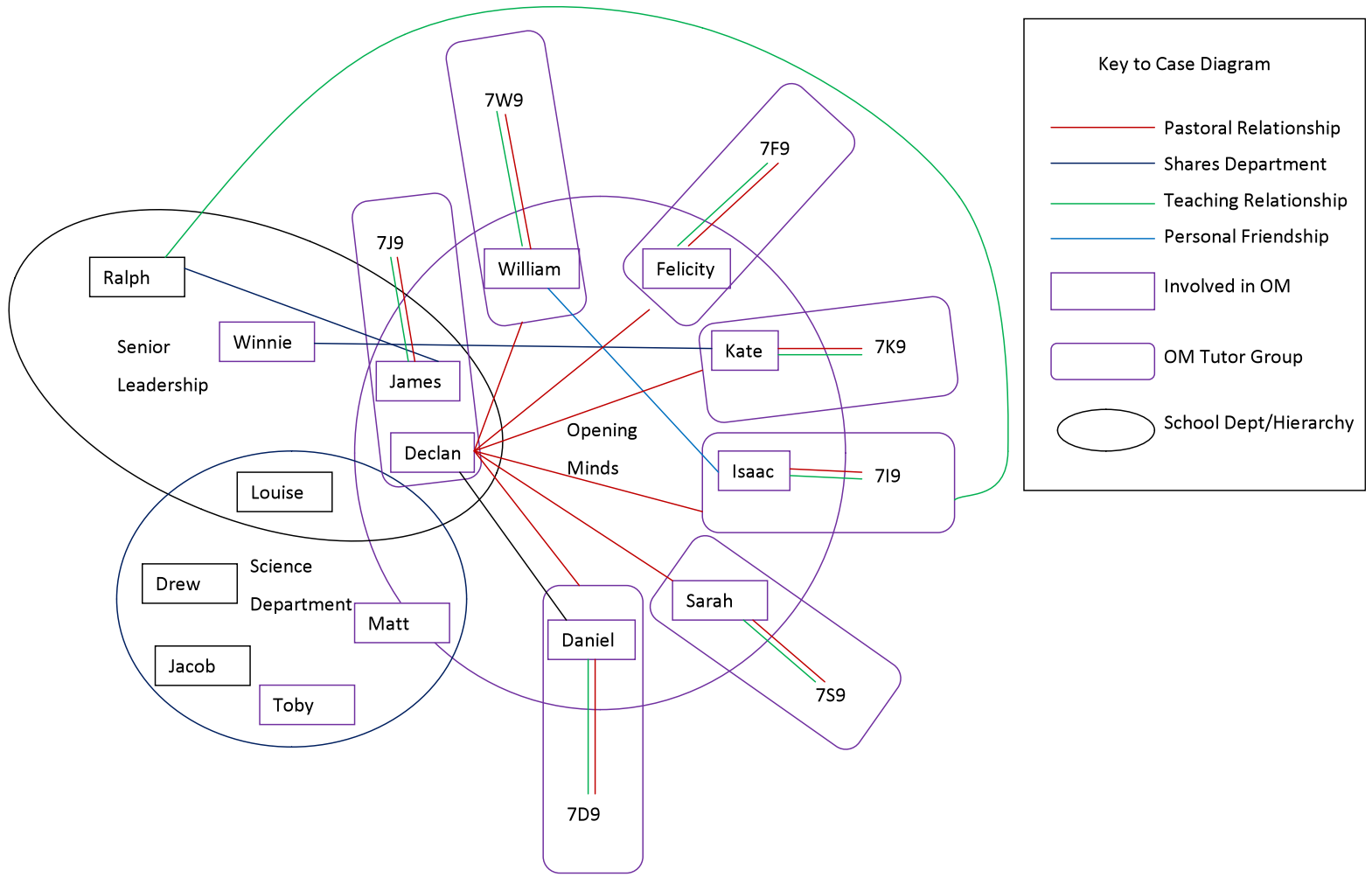

Figure 1: Case diagram 
I also made use of the insight from complexity thinking that breaking down a complex system into smaller analytical elements does not in fact make it any simpler (Cilliers, 1998; Davis E Sumara, 2006): individuals are complex system by themselves and their response to curriculum change, for example, is not necessarily simpler than that of a class or friendship group. In my research, I made use of this insight by attempting to focus on the enactment of the new curriculum at different levels, such as the curriculum materials developed, response to this curriculum by the year group as a whole, by classes, by teaching teams and by individuals (teachers and students). In this way, I looked for both patterns and dissonance in the data, such as commonalities of response among the year group (e.g., enjoying collaborative activities) compared with differences in response by different classes (e.g., one class using the freedom inherent in the new curriculum by choosing to work in more individualistic ways).

As the above writing in the illustrative examples of a complex case study approach shows, choices made by the researcher are a crucial aspect of any research, and this is no less important in case study. These choices may be influenced by the research focus, the changing case, and by the theoretical and epistemological perspective of the researcher. Researcher positioning in the case is of particular importance in a complexity thinking approach to case study due to the concept of complexity reduction, which I turn to next.

\section{Researcher positioning}

Within case study research, the positioning of the researcher and their role within the study is an aspect of discussion and debate. For some, an important strength of case study research is that it can represent the case authentically, on its own terms and through giving voice to the participants in the research. For others, such as constructionists, this notion can be criticized due to the impossibility of authentically presenting a phenomenon independently of one's construction or interpretation of it. Stake (1995) notes that in conducting case study, the researcher may take on multiple different roles, both consciously and unconsciously. The epistemological and theoretical positioning of the researcher therefore impacts on their choices in researching the case and in presenting that research.

The approach discussed in this paper suggests that in conducting research of a complex case study in education, the researcher must be situated within the case itself, as through interacting with the case, the emergent possibilities are altered since the case is always open to interactions within and between complex systems as cases. In conducting research, therefore, the researcher of necessity opens out the range of possible emergent trajectories, whilst at the same time closing others through the interaction of emergence and complexity reduction. As highlighted earlier, complexity can be reduced in various ways, with possible implications for emergence. An educational example might be reduction in complexity by seating students in rows, insisting they work in silence on structured tasks such as copying from the board, in contrast with a class where students work in diverse groups on open-ended questions with teacher facilitation of their exploration. Crucially however, in both of these scenarios there is still the potential for creativity, uncertainty and emergence, even if it might be considered less likely in the first than the second. This relates to the idea that complexity reduction is also a form of complexity production (Rasmussen, 2010), as any action that reduces complexity in social systems means weaving interactions together in different ways that have the potential to result in emergent phenomena.

Exploring education through a complexity lens therefore means paying attention to ways in which complexity is both reduced and produced in a system, and this concept is important in considering the positioning of the researcher and their role in collecting and interpreting the data gathered in case study research. In terms of methodological decision-making, this argument suggests that whilst it is necessary to reduce complexity in order to conduct research, the decisions taken in doing so also produce complexity in 
different ways. The researcher is part of the research in this framing of complexity and cannot be an external observer; the role of the researcher is to interact with a real, complex world and therefore have a role in making that world through their interactions. At the same time, it is important not to attempt to reduce the complexity of the research too far as this would effectively negate the complexivist perspective employed. This leads to an approach to case study in which the researcher role is explicitly part of the case. However, this is distinct from the constructionist understanding because complexity thinking does not imply that the case does not exist until it is constructed by the researcher, but rather that the researcher becomes part of the emerging trajectory of the case and, through their decision-making in research and in interaction with the case, both constrain and enable the emergent possibilities for that case.

For me, this stance necessitated an understanding that my undertaking this research involved making decisions about what and how to conduct the research that would, in my own understanding/interpretation, reduce the complexity of the system as I saw it whilst influencing in some ways the emerging development of the case. Numerous examples could be used to illustrate this, and I choose just two here. Firstly, in relation to choosing research methods, I initially chose to develop an observation schedule that was designed to help me focus the research on areas of interest while maintaining open space to respond to uncertainty. However, in practice I found this too constraining to use, finding that I was ignoring the structured element of the schedule and simple taking notes, so I moved to keeping open-ended field notes. This decision meant that during the research, I was both reducing and producing the complexity of my interpretation of the system differently as the research continued. Secondly, I found myself facing choices over how much to engage in discussion with teachers over the complexity perspective I was using in the research, and my focus of interest. At first, I was concerned that by engaging in this discussion, I would be effecting the case, thus compromising the authenticity of my study, but could not see a way to avoid doing so given that of necessity I needed to interact with the teachers and students to conduct the research. As I began to accept that from a complexity thinking perspective, this problematic was not in fact a problem, as my purpose was not to simply describe the case as though I was not there, but to become part of the complexity of the system and track the emergence of the curriculum with my role within it acknowledged. In doing so, I was able to engage in richer discussions with both teachers and pupils about the changing curriculum, and particularly the role of open-endedness alongside constraint, in ways that contributed to the development of the case as the teachers themselves began to engage in researching the curriculum from this and other perspectives in different ways than they otherwise might, in preparation for accreditation of their use of Opening Minds by the Royal Society of Arts. In this way, my role, though that of a researcher, moved closer to an action research perspective that has been discussed as an important means of conducting research rooted in complexity thinking (Phelps $\mathcal{E}$ Hase, 2002).

\section{Summary}

In discussing a complexity thinking approach to case study, I have used concepts of emergence and complexity reduction to illustrate the combination of both of these elements in the conduct of case study research. The use of case study described above enables the researcher to maintain a sensitivity to the open-ended and emergent within a case whilst at the same time acknowledging that in schools, and in research, processes of complexity reduction are ongoing. I have argued that a particular complexity thinking perspective has implications for the conduct of educational research, and that case study is one possible research approach to the exploration of complex systems in education that has rich potential. 
In any case study research, the epistemological commitments of the researcher impact on the decisions made about the conduct of research, despite case study approaches having in common a focus on study-in-depth around a particular area of interest. I suggest that a complexity thinking approach to case study can be viewed as distinct from, though similar to, other case study approaches, drawing out particular distinctions in relation to key debates about causality and prediction, setting the boundaries of the case, and the positioning of the researcher in relation to the case. The theoretical discussion in this paper, combined with some illustrative examples drawn from a 'complexity thinking case study', therefore aimed to provide insight for researchers considering using case study from a complexity theoretical perspective to explore classroom practice. It also aimed to identify, for those familiar with case study but less so with complexity theories, ways in which such an approach might offer an alternative conception of case study research that may be of interest. In summary, the result of the arguments presented in this paper is a research approach, which attempts to cohere the research around a particular topic without closing down the 'goals' of the research (as complex systems are open-ended); which is focused on particular levels of emergence that are of interest and explored through particular techniques deemed appropriate for those interests and levels; in which the researcher is a part; and in which the research remains open to unanticipated paths which may emerge in the course of the research ${ }^{6}$.

\section{References}

Alhadeff-Jones, M. (2008). Three generations of complexity theories: Nuances and ambiguities. Educational Philosophy and Theory, 40(1), 66-82.

Alhadeff-Jones, M. (2012). Learning disorders: From a tragic to an epic perspective on complexity. Complicity: An International Journal of Complexity \& Education, 9(2), i-vi.

Biesta, G. (2010). Five theses on complexity reduction and its politics. In D. Osberg \& G. Biesta (Eds.), Complexity theory and the politics of education (pp. 5-13). Rotterdam: Sense.

Biesta, G., \& Osberg, D. (2007). Beyond re/presentation: A case for updating the epistemology of Schooling. Interchange, 38(1), 15-29.

Byrne, D. (2005). Complexity, configurations and cases. Theory, Culture \& Society, 22(5), 95-111.

Chadderton, C., \& Torrance, H. (2011). Case study. In B. Somekh \& C. Lewin (Eds.), Theory and methods in social research (pp. 53-60). London: Sage.

Cilliers, P. (1998). Complexity and postmodernism: Understanding complex systems. New York: Routledge.

Cohen, L., Manion, L., \& Morrison, K. (2007). Research methods in education (6th Edition ed.). London and New York: RoutledgeFalmer.

Davis, B., \& Sumara, D. (2006). Complexity and education: Inquiries into teaching, learning and research. Mahwah, NJ: Lawrence Erlbaum Associates.

Fenwick, T. (2010). Normalising standards in educational complexity: A network analysis. In D. Osberg \& G. Biesta (Eds.), Complexity theory and the politics of education (pp. 57-67). Rotterdam: Sense.

Frelin, A., \& Grannas, J. (2010). Negotiations left behind: in-between spaces of teacher-student negotiation and their significance for education. Journal of Curriculum Studies, 42(3), 353-369.

Gomm, R., Hammersley, M., \& Foster, P. (Eds.). (2000). Case study methods: Key issues, key texts. London: Sage.

Haggis, T. (2008). Knowledge must be contextual: some possible implications of complexity and dynamic systems theories for educational research. Educational Philosophy and Theory, 40(1), 158176.

Hammersley, M. (2004). Case study. In M. S. Lewis-Beck, A. Bryman \& T. F. Liao (Eds.), Encyclopedia of social science research methods. (pp. 93-95). Thousand Oaks, CA: Sage.

Hetherington, L. (2012). "Walking the line between structure and freedom": A case study of teachers' responses to curriculum change using complexity theory. (Doctor of Philosophy), University of Exeter, University of Exeter. Retrieved from http:/ / hdl.handle.net/10036/3868

\footnotetext{
${ }^{6}$ Such unanticipated paths that might be followed have been discussed in some complexity and education literature as 'lines of flight', or 'rhizomes', following the work of Deleuze and Guattari. This work has not been directly taken up in this paper due to lack of space.
} 
Hitchcock, G., \& Hughes, D. (1995). Research and the teacher (Second Edition ed.). London: Routledge.

Kincheloe, J. (2001). Describing the bricolage: Conceptualizing a new rigor in qualitative research. Qualitative Inquiry, 7(6), 679-692.

Kincheloe, J. (2005). On to the next level: Continuing the conceptualization of the bricolage. Qualitative Inquiry, 11(3), 323-350.

Kincheloe, J., \& Berry, K. (2004). Rigour and complexity in educational research: Conceptualizing the bricolage. Maidenhead: Open University Press.

Kuhn, L. (2008). Complexity and educational research: a critical reflection. Educational Philosophy and Theory, 40(1), 177-189.

Law, J. (2004). After method: Mess in social science research. London: Routledge.

McCall, L. (2005). The complexity of intersectionality. Signs: Journal of Women in Culture and Society, 30(3), 1771-1800.

Merriam, S. B. (1988). Case study research in education. San Francisco, CA: Jossey Bass.

Morrison, K. (2008). Educational philosophy and the challenge of complexity theory. Educational Philosophy and Theory, 40(1), 19-34.

Osberg, D. (2005). Curriculum, complexity and representation: Rethinking the epistemology of schooling through complexity theory. (Ph.D Educational Theory), The Open University, Milton Keynes.

Osberg, D. (2008). The logic of emergence: An alternative conceptual space for theorizing critical education. Journal of the Canadian Association for Curriculum Studies, 6(1), 133-161.

Osberg, D., \& Biesta, G. (2007). Beyond presence: Epistemological and pedagogical implications of "strong" emergence. Interchange, 38(1), 31-51.

Osberg, D., Biesta, G., \& Cilliers, P. (2008). From representation to emergence: complexity's challenge to the epistemology of schooling. Educational Philosophy and Theory, 40(1), 213-227.

Phelps, R., \& Hase, S. (2002). Complexity and action research: Exploring the theoretical and methodological implications. Educational Action Research, 10(3), 507-524.

Pinar, W. F., \& Irwin, R. L. (Eds.). (2005). Curriculum in a new key: The collected works of Ted T. Aoki. Mahwah, NJ: Lawrence Erlbaum.

Rasmussen, J. (2010). Increasing complexity by reducing complexity: A luhmannian approach to learning. In D. Osberg \& G. Biesta (Eds.), Complexity theory and the politics of education (pp. 15-24). Rotterdam: Sense.

Richardson, K., \& Cilliers, P. (2001). What is complexity science? A view from different directions. Emergence, 3(1), 5-22.

RSA. (2008-2012). Opening minds. Retrieved 19/3/2012, from http: / / www.rsaopeningminds.org.uk/ about-rsa-openingminds /

Simons, M., \& Olssen, M. (2010). The school and learning apparatus. In D. Osberg \& G. Biesta (Eds.), Complexity Theory and the Politics of Education (pp. 79-91). Rotterdam: Sense.

Smitherman. (2008). Bifurcations are not always exclusive. Complicity: An International Journal of Complexity \& Education, 5(1), 125-128.

Stake, R.E. (1994). Case studies. In N. K. Denzin \& Y. S. Lincoln (Eds.), Handbook of qualitative research (pp. 236-247). London: SAGE.

Stake, R.E. (1995). The art of case study research. Thousand Oaks, CA: SAGE.

Stake, R.E. (2005). Qualitative case study. In N. K. Denzin \& Y. S. Lincoln (Eds.), Sage handbook of qualitative research (pp. 443-466). Thousand Oaks, CA: SAGE.

Stenhouse, L. (1985). Case study methods. In T. Husen \& T. N. Postlethwaite (Eds.), International encyclopedia of education (First ed., pp. 640-646). Oxford: Pergamon.

Yin, R. K. (1984). Case study research: Design and methods. Beverley Hills, CA: Sage. 


\title{
Acknowledgments
}

The research reported here was completed as part of a $\mathrm{PhD}$ thesis supported by the University of Exeter as part of a Teacher Education Research Fellowship. I am grateful for the advice and support of Deborah Osberg and Keith Postlethwaite throughout.

\begin{abstract}
About the Author
Lindsay Hetherington is a Lecturer in Science Education at Exeter University, UK. Her research focuses on using complexity theory to explore pedagogy in the context of learning to learn and science education. She is also involved in science education research, exploring dialogic approaches to learning, the implications of complexity theory for science teacher education, and the implications of complexity perspectives for research methodology. She can be contacted at L.Hetherington@exeter.ac.uk.
\end{abstract}

(c) Copyright 2013. The author, LINDSAY HETHERINGTON, assigns to the University of Alberta and other educational and nonprofit institutions a non-exclusive license to use this document for personal use and in courses of instruction provided that the article is used in full and this copyright statement is reproduced. The author also grants a non-exclusive license to the University of Alberta to publish this document in full on the World Wide Web, and for the document to be published on mirrors on the World Wide Web. Any other usage is prohibited without the express permission of the authors. 